\title{
Laboratory Evaluation of Selected Differential Chemistry Synthetic Insecticides against some Economically Important Insect Pests
}

\author{
Muhammad Zeeshan Majeed ${ }^{1 *}$, Muhammad Irfan Ullah¹, Dilbar Hussain ${ }^{2}$, Muhammad Luqman $^{3}$, Mu- $^{-}$ \\ hammad Qasim ${ }^{1}$, Gulfam Yousaf ${ }^{1}$, Hamza Latif $^{1}$ and Muhammad Zeeshan ${ }^{1}$
}

${ }^{1}$ Department of Entomology, College of Agriculture, University of Sargodha, 40100 Sargodha, Pakistan; ${ }^{2}$ Entomological Research Institute, Ayub Agricultural Research Institute, 38850 Faisalabad, Pakistan; ${ }^{3}$ Department of Agricultural Extension, College of Agriculture, University of Sargodha, 40100 Sargodha, Pakistan.

Abstract | Contemporary non-target effects of conventional synthetic insecticides necessitate evaluating biorational insecticides owing differential chemistry and modes of action than the conventional ones. This laboratory study comparatively evaluated some selected differential chemistry insecticides against some destructive and economically important insect pests i.e. mango mealybug (Drosicha mangiferae Green), mango leafhopper (Idioscopus clypealis Lethierry), Asian citrus psyllid (Diaphorina citri Kuwayama) and subterranean termites (Odontotermes obesus Rambur). Standard twig- and filter paper-dip bioassay methods were used against sap-feeding pests and termites, respectively. Factorial analyses of variance revealed a significant impact of tested insecticidal formulations and exposure time on the mortality all insect pest individuals. The most effective differential chemistry insecticides against mango leafhopper, citrus psyllids, mango mealybugs and subterranean termites were nitenpyram, clothianidin, thiamethoxam and imidacloprid (causing 74-79\% cumulative corrected mortality), thiamethoxam, imidacloprid, clothianidin and spirotetramat (causing 78-85\% cumulative mortality), spirotetramat, acetamiprid and thiamethoxam (causing 68-90\% cumulative mortality), and chlorantraniliprole, pyriproxyfen and chlorfenapyr (causing 80-85\% cumulative mortality), respectively. Overall study findings suggest these above mentioned non-conventional insecticides to be incorporated in the biorational management of these insect pests.

Received | May 24, 2021; Accepted | October 15, 2021; Published | January 12, 2022

*Correspondence | Muhammad Zeeshan Majeed, Department of Entomology, College of Agriculture, University of Sargodha, 40100 Sargodha, Pakistan; Email: zeeshan.majeed@uos.edu.pk

Citation | Majeed, M.Z., M.I. Ullah, D. Hussain, M. Luqman, M. Qasim, G. Yousaf, H. Latif and M. Zeeshan. 2021. Laboratory evaluation of selected differential chemistry synthetic insecticides against some economically important insect pests. Pakistan Journal of Agricultural Research, 34(4): 878-888.

DOI | https://dx.doi.org/10.17582/journal.pjar/2021/34.4.878.888

Keywords | Biorational pesticides, Differential chemistry insecticides, Diaphorina citri, Drosicha mangiferae, Idioscopus clypealis, Odontotermes obesus, In-vitro toxicity

\section{Introduction}

$I$ nsect pests have always been a ubiquitous threat to global food production. These invertebrates cause untold qualitative and quantitative damage to various agricultural and horticultural crops all over the world including India and Pakistan (Arif et al., 2018; Gun- dappa and Shukla, 2018). Almost all field and forage, fruit and vegetable and forest and ornamental crops are attacked by different sucking and chewing insect pests. For instance, mango mealybug (Drosicha mangiferae Green), mango leafhopper (Idioscopus clypealis Lethierry), Asian citrus psyllid (Diaphorina citri Kuwayama) and subterranean termites (Odontotermes 
obesus Rambur) are among the most destructive insect pest species and are of great economic importance under agro-climatic conditions of Pakistan.

Mango mealybug ( $D$. mangiferae) is a polyphagous species attacking a wide range of horticultural and agricultural plants. Since last few decades, this mealybug species has acquired a status of regular pest of many fruit crops including citrus and mango in Pakistan and causes considerable direct and indirect losses to these crops (Tahir et al., 2015; Mirbahar et al., 2017; Ghafoor et al., 2020). Mango leafhopper (I. clypealis) is also a major sap-sucking insect pest and poses a great menace to mango crop in the country (Gundappa and Shukla, 2016; Karar and Bakhsh, 2018). Adults and nymphs of mango leafhopper infest gregariously at the flowering stage and cause considerable economic damage to mango crop each year (Jha et al., 2017; Karar and Bakhush, 2018).

Similarly, Asian citrus psyllid (D. citri) has been the challenging pest of citrus all over the world including Pakistan. Desaping of plants by both adults and nymphs of this species cause severe losses to citrus crop (Mahmood et al., 2014). Apart from direct sap-feeding, this pest is a notorious vector of citrus greening, a destructive disease of citrus orchards (Teixeira et al., 2005; Razi et al., 2014; Canale et al., 2017). Similarly, subterranean termites (O. obesus and other species) infest a number of agricultural, horticultural and forestry crops and damage wooden works in agricultural and urban settings (Manzoor et al., 2012; Majeed, 2012; Ahmed et al., 2013). They attack and damage many agricultural and fruit crops including gram, sesame, maize, cotton, wheat, sugarcane, citrus and mango (Iqbal and Saeed, 2013; Rasib et al., 2017).

In order to combat and suppress these insect pests' infestations, farmers in Pakistan rely exclusively on highly toxic and persistent conventional synthetic pesticides (Ahmed et al., 2006; Akbar et al., 2010; Tiwari et al., 2011; Manzoor et al., 2012; Gulzar et al., 2015; Ghafoor et al., 2020). Extensive and repeated use of these conventional synthetic insecticides is posing many non-target effects on the human health and environment (Edwards, 2013; Chowański et al., 2014; Nicolopoulou-Stamati et al., 2016). Moreover, many of the field populations of mango leafhopper, mealybugs, citrus psyllids and subterranean termites have been demonstrated to exhibit resistance against these conventional insecticides (Tiwari et al., 2011;
Tong et al., 2013; Afzal et al., 2015; Naeem et al., 2016; Venkatesan et al., 2016; Mahapatro, 2017).

Although synthetic insecticides have been unavoidable plant protection option to ensure sustained agricultural production, it is imperative to search for novel insect pest management approaches which would be biorational and safer than the conventional insecticides. For instance, there are many soft insecticides available in the market since last few decades which have a different mode of action and chemistry than the conventional ones, and are more target specific, less toxic to non-target fauna and are usually quickly biodegradable (Ishaaya and Degheele, 2013; Oberemok et al., 2015; Singh et al., 2016). This laboratory work determined the comparative effectiveness of some available insecticidal formulations with differential chemistry against above mentioned insect pests using standard laboratory bioassay methods.

\section{Materials and Methods}

\section{Culture of insect pests}

Mango leafhopper (I. clypealis) adults were collected from a mango orchard of Faisalabad (73 4 '44.79" E; $\left.31^{\circ} 25^{\prime} 7.37^{\prime \prime} \mathrm{N}\right)$ using aerial nets. Adults of female mealybugs (D. mangiferae) and Asian citrus psyllids were collected manually and by aspirator, respectively, from a kinnow mandarin orchard (Citrus reticulata) situated nearby College of Agriculture, University of Sargodha $\left(72^{\circ} 41^{\prime} \mathrm{E} ; 32^{\circ} 08^{\prime} \mathrm{N}\right)$. Subterranean termites (O. obesus) were collected along with their intact nest portions from the stubbles of sugarcane crop $\left(72^{\circ} 45^{\prime} \mathrm{E} ; 32^{\circ} 11^{\prime} \mathrm{N}\right)$ situated at the farm area of the College of Agriculture. These collected insects were carried under cool conditions to the laboratory and were maintained and reared up to $\mathrm{F}_{2}$ or $\mathrm{F}_{3}$ generations on their respective food sources separately in insect rearing $\left(\right.$ Bugdorm $\left.{ }^{\circ}\right)$ cages $\left(2 \times 3 \times 1.5 \mathrm{ft}\right.$.) at $27 \pm 2^{\circ} \mathrm{C}$ temperature and $65 \pm 5 \%$ relative humidity. In all toxicity bioassays, only healthy and active insect specimens were used.

\section{Insecticides procurement}

Based on literature and survey of pesticides dealers in the grain markets of district Sargodha (Punjab, Pakistan), six contact and nine systemic synthetic insecticide formulations with differential chemistry (other than conventional insecticide groups) were selected. Commercial formulations of selected synthetic insecticides with differential chemistry were procured from 
authenticated pesticide retailers. Details regarding the brand and company names, mode of action, chemical group and family and label recommended dose rates of these selected insecticides are given in Table 1.

\section{Bioassays}

A total of nine and six synesthetic insecticides (including neonicotinoids, insect growth regulators and others) were evaluated against sucking insect pests and termites, respectively. Standard leaf- and twigdip bioassay methods were followed for mango leafhopper, citrus psyllids and mealybugs, respectively as described previously (Majeed et al., 2020). For termites, standard filter paper-dip method was used. In brief, for sucking insect pests, $5 \mathrm{~cm}$ long unsprayed twig tips of citrus (C. reticulata) or mango (Mangifera indica) plants were collected, rinsed thoroughly using tap-water and then were allowed to be drained at $28^{\circ} \mathrm{C}$ (prevailing room temperature). For termites, 9 $\mathrm{cm}$ filter paper discs were used. These twigs and filter papers were dipped in insecticide solutions prepared according to their label recommended dose rates. Control treatment received clean tap-water which was used for preparing the insecticide solutions. Ten healthy and active insect specimens (nymphs or adults as per insect pest species) were placed on the treated plant twigs or filter paper discs lined in Petri-plates $(\varnothing=90 \mathrm{~mm}$ ). These Petri-plates were stacked in plastic laboratory trays and were incubated within a climate chamber set at $65 \pm 3 \%$ relative humidity, $27 \pm 2{ }^{\circ} \mathrm{C}$ temperature and at $8 \mathrm{~h}: 16 \mathrm{~h}$ dark-light photoperiod. The mortality data of exposed insect specimens were recorded at regular time intervals i.e. at 6, 12, 24, 48 and $72 \mathrm{~h}$ post-treatment. Experimental design for all toxicity bioassays was completely randomized (CRD) and each treatment was replicated six times.

\section{Statistical analyses}

Statistical interpretation of the bioassays' data was done using Statistix ${ }^{\otimes}$ Version 8.1 (Analytical Software, Tallahassee, FL) was employed for the. Before statistical analysis, percent mortality data of all four insect species were corrected using Abbott's formula. In order to determine the significant effect of tested insecticidal formulations on insect pests, corrected mortality data were analyzed by factorial ANOVA (analysis of variance) taking exposure time and insecticides as factors. Furthermore, Tukey's HSD (honestly significant difference) post-hoc test was used to compare the treatment means at standard probability level $(P \geq 0.05)$.

\section{Results and Disussion}

This laboratory study determined the comparative toxicity of different contemporary differential chemistry synthetic and contact insecticide formulations against four destructive and economically important insect pests i.e. mango leafhopper (I. clypealis), Asian citrus psyllid (D. citri), mango mealybug (D. mangiferae) and subterranean termites ( $O$. obesus) using standard in-vitro bioassay methods.

\section{Mortality of mango leafhopper by synthetic insecticides}

Factorial analysis of variance subjected to mortality percentage of mango leafhopper adults bioassayed against different selected systemic synthetic insecticides showed a significant impact of both insecticidal treatments $\left(\mathrm{F}_{(8,215)}=41.64, P<0.001\right)$, time factors $\left(\mathrm{F}_{(3,215)}=76.56, P<0.01\right)$, and their interaction $\left(\mathrm{F}_{(24,}\right.$ $\left.\left.{ }_{215}\right)=3.99, P<0.001\right)$ on the leafhoppers' mortality response (Table 2). A significant mortality of the exposed leafhopper individuals was recorded for all insecticidal treatments as compared to control treatment. Maximum mortality observed at $48 \mathrm{~h}$ post-exposure was exhibited by nitenpyram (78.67\%), followed by clothianidin, thiamethoxam, imidacloprid and pymetrozine $(74.68 \%$ each), while the insecticides buprofezin (24.25\%) and acetamiprid (56.67\%) were least toxic against leafhoppers (Figure 1).

\section{Mortality response of Asian citrus psyllid against tested insecticides}

According to factorial ANOVA and Tukey HSD test, there was a significant effect of both insecticidal treatments $\left(\mathrm{F}_{(8,215)}=95.66, P<0.001\right)$ and time $\left(\mathrm{F}_{(3,215)}=\right.$ 336.86, $P<0.05)$ factors and their interaction $\left(\mathrm{F}_{(24,}\right.$ $\left.{ }_{215)}=10.40, P<0.001\right)$ on the mortality response of psyllids (Table 2). At $48 \mathrm{~h}$ of bioassay, the most toxic differential chemistry systemic insecticides against psyllids were thiamethoxam, imidacloprid, clothianidin and spirotetramat causing up to $85.10 \%$ mortality. While the insecticides flonicamid, buprofezin and pymetrozine exhibited minimum psyllid mortality (up to 31.67\%; Figure 2).

\section{Toxicity of tested insecticides against mango mealybug}

In case of toxicity bioassay against $2^{\text {nd }}$ instar mealybug individuals, again both factors i.e. insecticidal treatments $\left(\mathrm{F}_{(8,215)}=70.88, P<0.001\right)$ and time $\left(\mathrm{F}_{(3,215)}=267.76, P<0.05\right)$ and their interaction $\left(\mathrm{F}_{(24,}\right.$ $\left.{ }_{215)}=9.61, P<0.001\right)$ showed statistically considerable impact on the mortality response of mealybug 


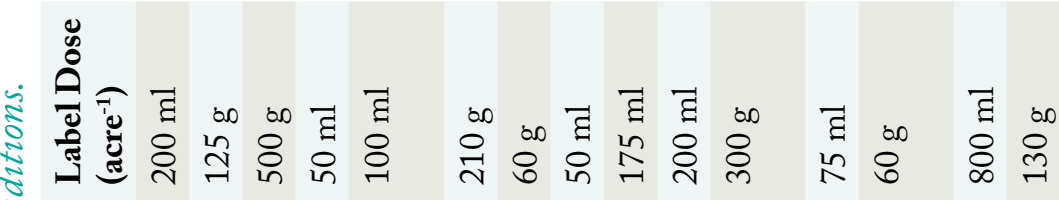

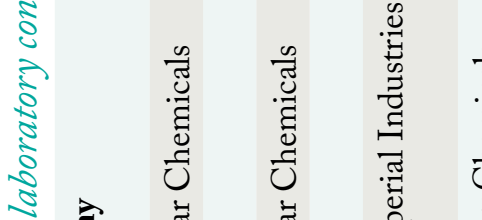

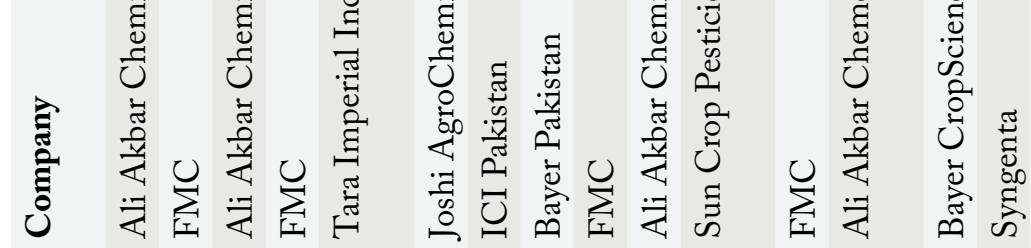

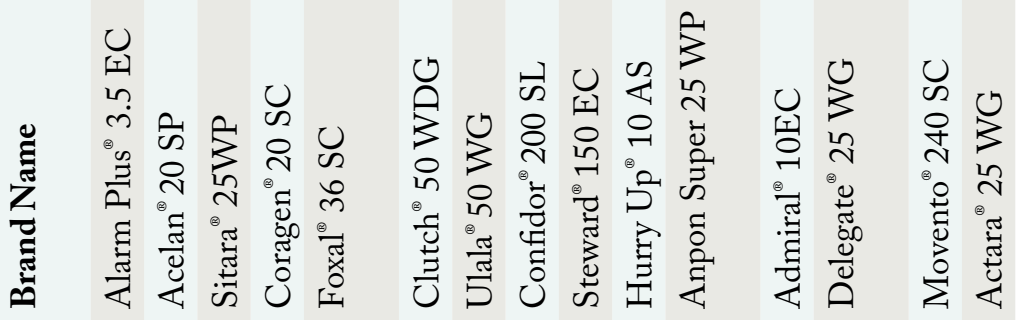

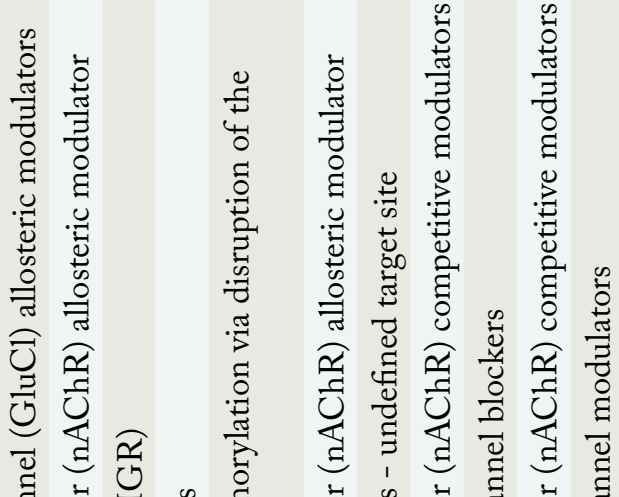

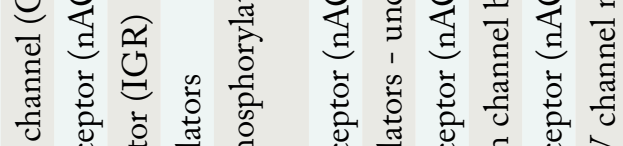

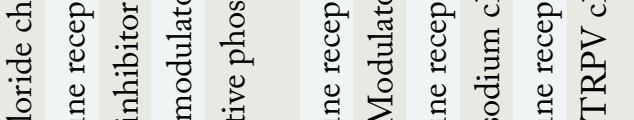

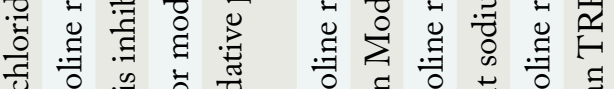

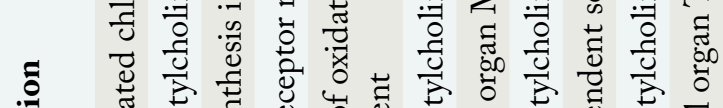

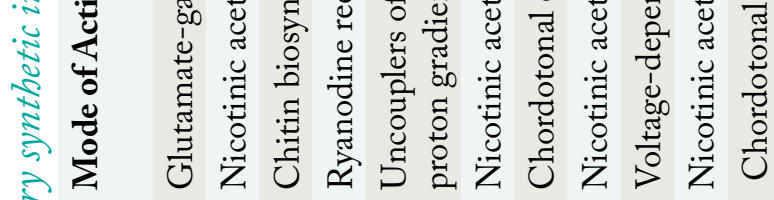

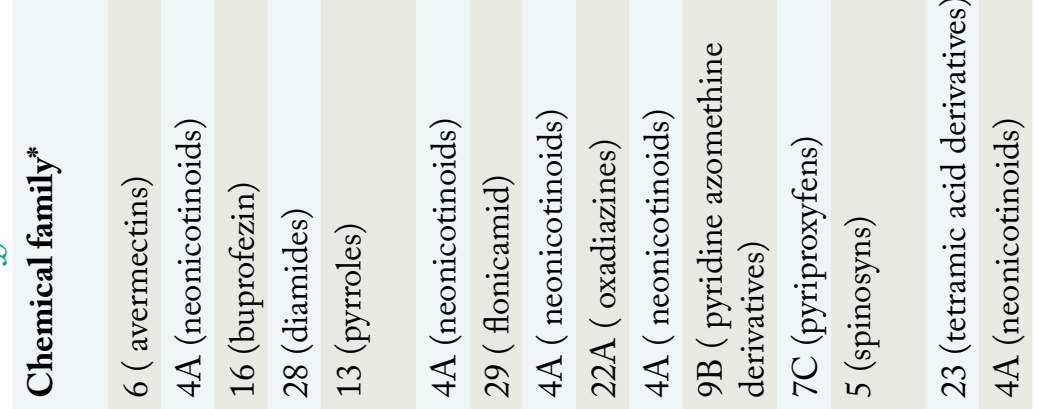

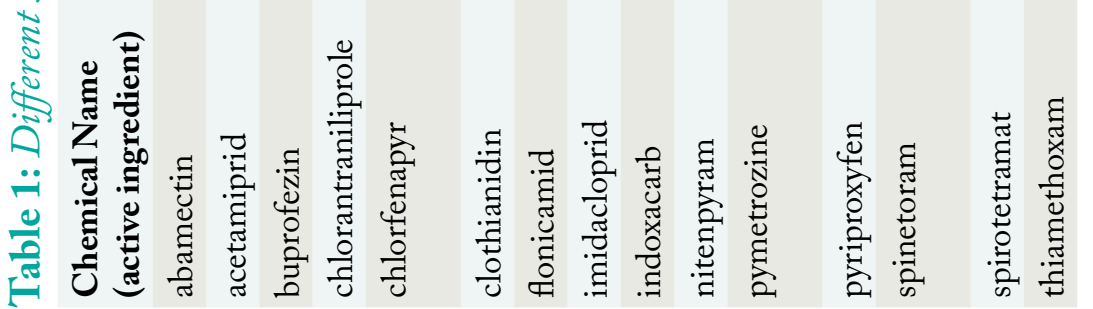

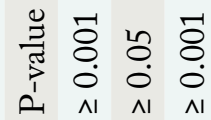

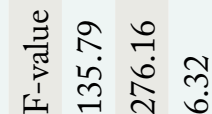

oे

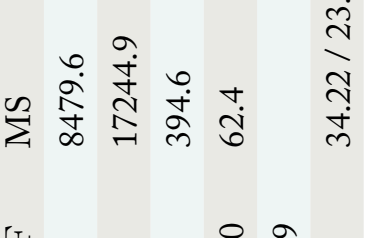

듑

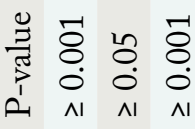

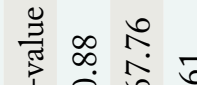

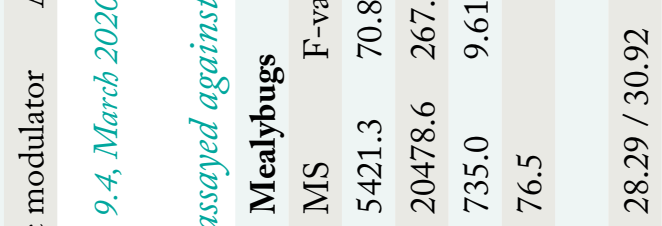

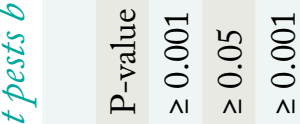

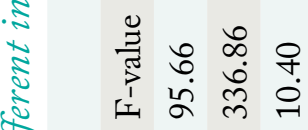

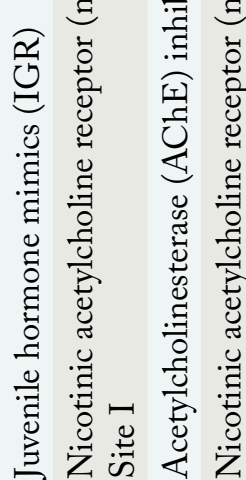

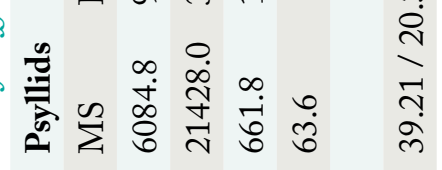

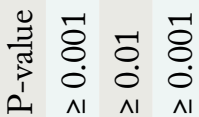

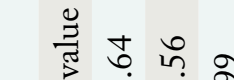

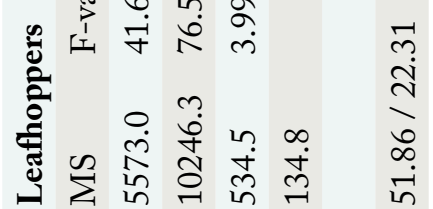

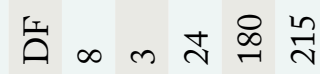

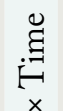

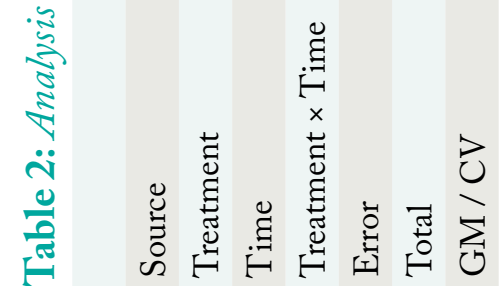




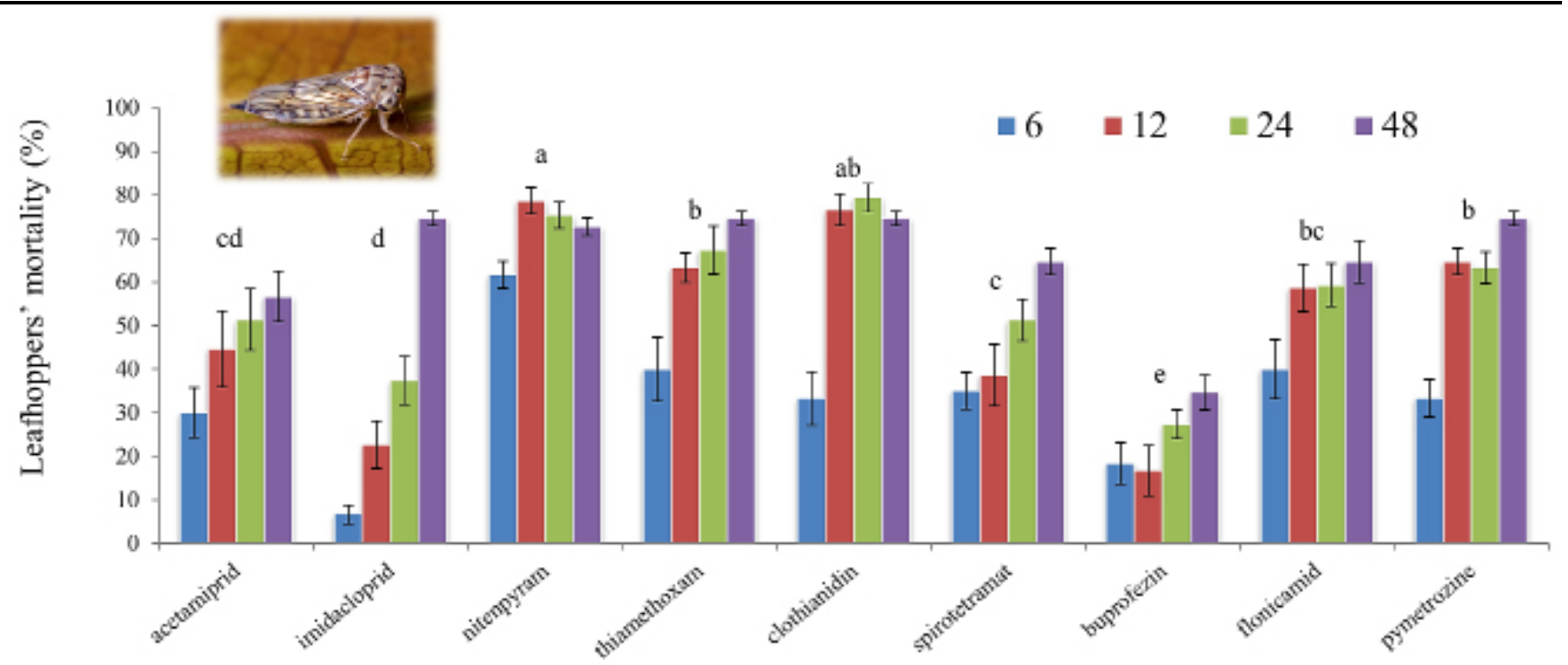

Insecticides

Figure 1: Percent corrected mortality (mean \pm S.E.) of adult individuals of mango leafhopper (Idioscopus clypealis) bioassayed against different differential-chemistry synthetic insecticides at their label recommended dose rates. Different letters indicate overall significant difference among the insecticidal treatments (two-factor factorial analysis of variance followed by HSD test at P $\geq 0.05$ ).

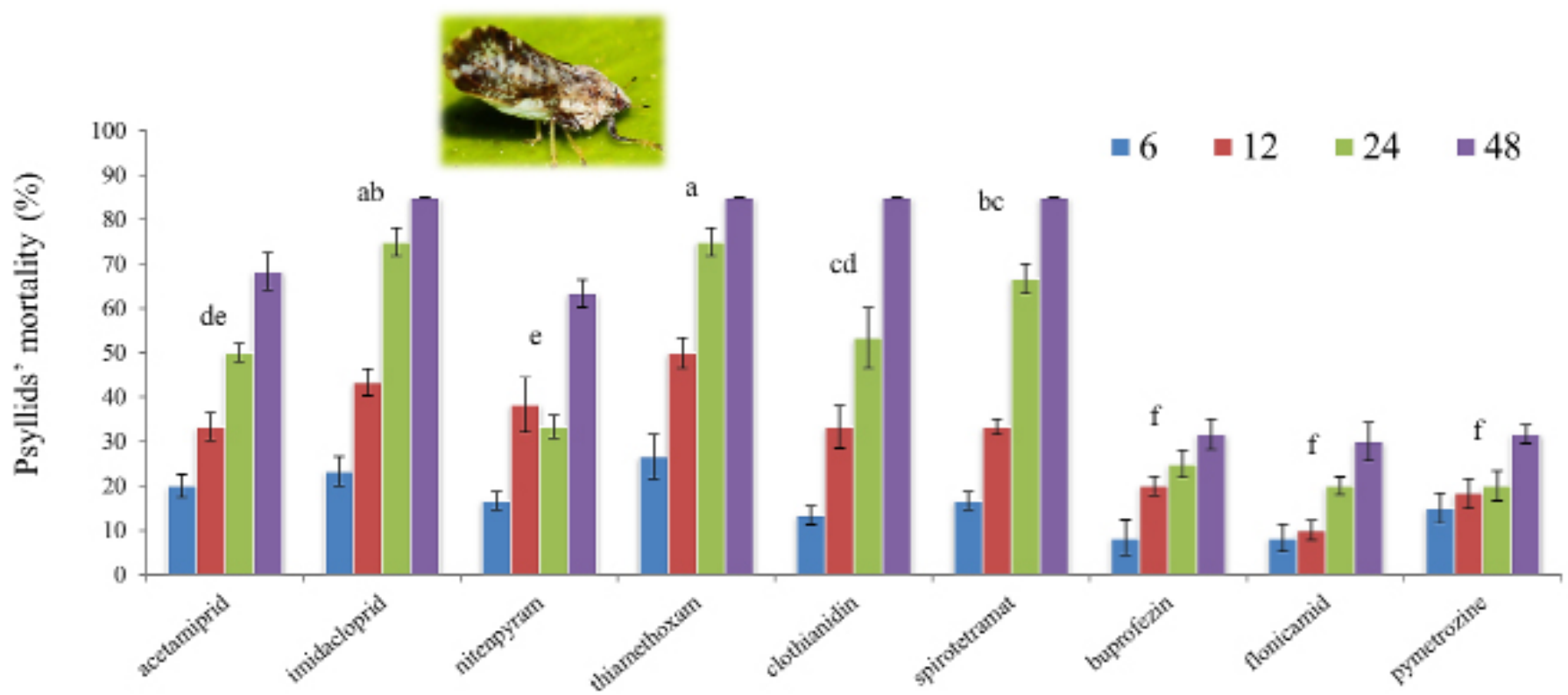

Insecticides

Figure 2: Percent corrected mortality (mean \pm S.E.) of adult individuals of Asian citrus psyllid (Diaphorina citri) bioassayed against different differential-chemistry synthetic insecticides at their label recommended dose rates. Different letters indicate overall significant difference among the insecticidal treatments (two-factor factorial analysis of variance followed by HSD test at $P \geq 0.05$ ).

individuals (Table 2). Maximum mealybug mortality was caused by the insecticides spirotetramat $(90.00 \%)$ and acetamiprid (86.67\%), followed by thiamethoxam (68.33\%) and imidacloprid (58.33\%), while insecticides flonicamid, buprofezin, nitenpyram and pymetrozine were the least effective insecticides against mealybug individuals causing $17-42 \%$ mortality recorded at $72 \mathrm{~h}$ post-exposure (Figure 3 ).

\section{Effect of insecticides on subterranean termites}

Bioassay conducted against $O$. obesus termite workers revealed a similar trend of insecticidal toxicity. According to ANOVA, both factors i.e. insecticides $\left(\mathrm{F}_{(5}\right.$, 179) $=135.79, P<0.001)$ and time $\left(\mathrm{F}_{(4,179)}=276.16, \stackrel{S}{P}\right.$ $<0.05)$, and the interaction of both these factors $\left(\mathrm{F}_{(20 \text {, }}\right.$ $\left.{ }_{179)}=6.32, P<0.001\right)$ exerted a significant impact on the average percent mortality of termite individuals 


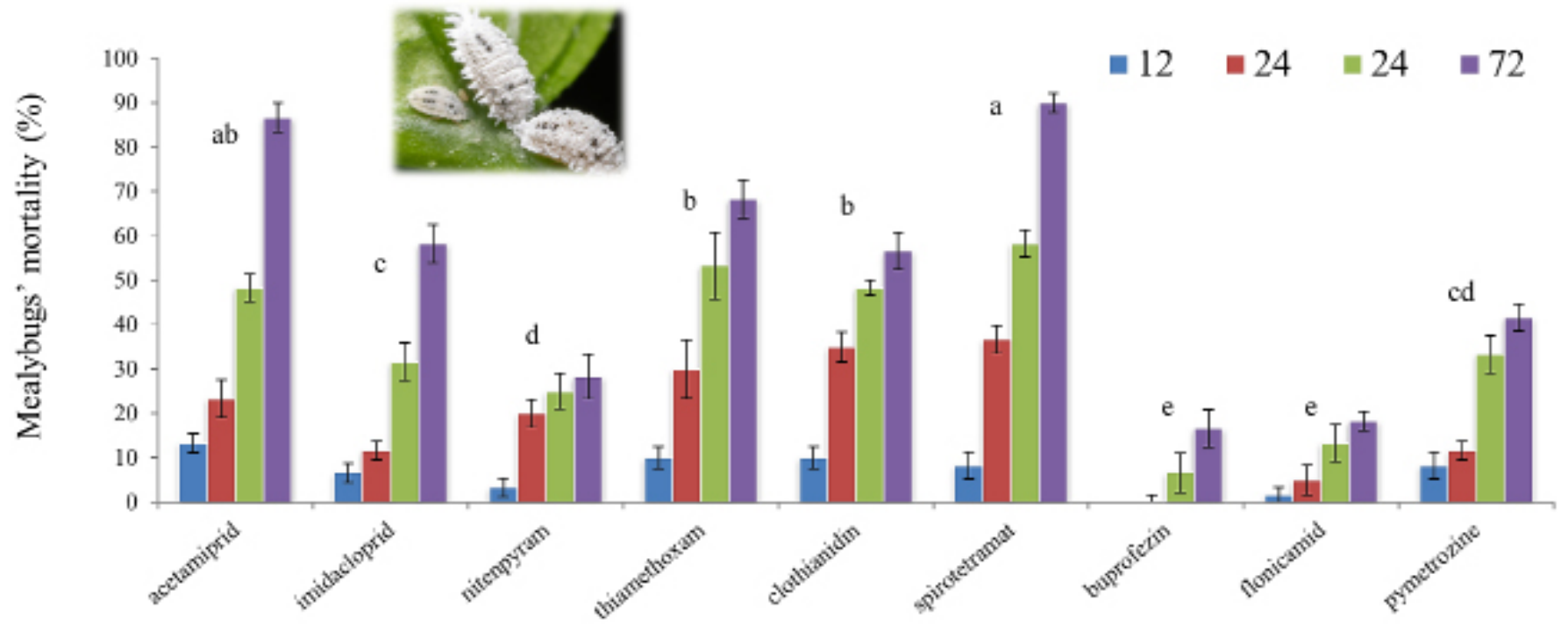

Insecticides

Figure 3: Percent corrected mortality (mean \pm S.E.) of $3^{\text {rd }}$ instar female individuals of mango mealybug (Drosicha mangiferae) bioassayed against different differential-chemistry synthetic insecticides at their label recommended dose rates. Different letters indicate overall significant difference among the insecticidal treatments (two-factor factorial analysis of variance followed by HSD test at $P \geq 0.05$ ).

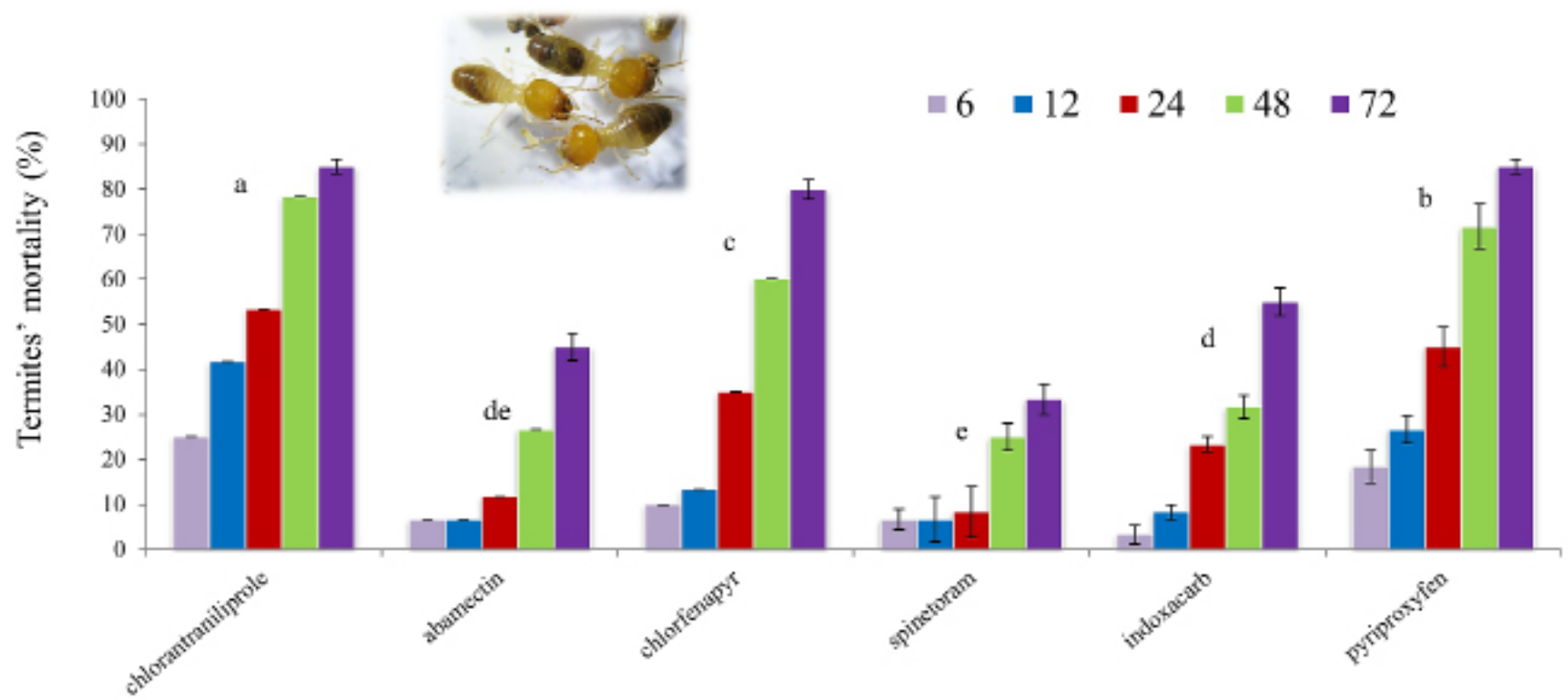

Insecticides

Figure 4: Percent corrected mortality (mean \pm S.E.) of worker individuals of subterranean termites (Odontotermes obesus) bioassayed against different differential-chemistry synthetic insecticides at their label recommended dose rates. Different letters indicate overall significant difference among the insecticidal treatments (two-factor factorial analysis of variance followed by HSD test at $P \geq 0.05$ ).

(Table 2). Most effective and toxic synthetic insecticides appeared against $O$. obesus termites were chlorantraniliprole and pyriproxyfen each causing $85.00 \%$ average mortality observed at $72 \mathrm{~h}$ of bioassay, followed by chlorfenapyr (80\%). While the insecticides spinetoram (33.33\%) and abamectin (45.20\%) were least effective against $O$. obesus termite workers (Figure 4).
This laboratory work compared the effectiveness of nine contemporary differential chemistry systemic insecticides against mango leafhopper (I. clypealis), mealybugs ( $D$. mangiferae) and citrus psyllids ( $D$. citri) and six contact insecticides against subterranean termites (O. obesus). Bioassay results revealed that the insecticides nitenpyram, clothianidin, thiamethoxam and imidacloprid were most effective against mango 
leafhopper (I. clypealis) which exhibited about 74 $79 \%$ cumulative mortality of leafhopper adults within $48 \mathrm{~h}$ of exposure. These findings substantiate the findings of Qureshi et al. (2011), Kaushik et al. (2014) and Kumar et al. (2019) showing the effectiveness of imidacloprid and thiamethoxam against leafhoppers and other sap-sucking insect pests of mango trees. Neonicotinoids are systemic insecticides which have always been effective chemical tools against different species of sap-feeding insect pests including I. clypealis (Elbert et al., 2008).

Similarly, most effective differential chemistry insecticides against Asian citrus psyllids (D. citri) were thiamethoxam, imidacloprid, clothianidin and spirotetramat causing $78-85 \%$ mortality of psyllids in $48 \mathrm{~h}$ of bioassay. These results are consistent with the findings of some previous works (Stansly and Qureshi, 2007; Khan et al., 2013; Byrne et al., 2017; Fiaz et al., 2018a). These insecticides have been shown effective under field conditions against $D$. citri and many other sap-feeding insect pests (Nazir et al., 2017; Fiaz et al., 2018b; Ghafoor et al., 2019; Iqbal et al., 2020).

In mealybug bioassay, insecticides spirotetramat, acetamiprid and thiamethoxam were found as the most effective against $2^{\text {nd }}$ instar mealybug nymphs causing $68-90 \%$ average mortality in $72 \mathrm{~h}$. These results are consistent with the those of Ghafoor et al. (2019) which demonstrated about 62 and 53\% mortality of $2^{\text {nd }}$ instar mealybug nymphs by spirotetramat and thiamethoxam, respectively. These insecticides appeared also effective against mealybugs under the field conditions (Ghafoor et al., 2020). Apart from D. mangiferae, spirotetramat insecticide was found effective against other mealybug species such as against pink hibiscus mealybug (Maconellicoccus hirsutus) and cotton mealybug (Phenacoccus solenopsis) under field and laboratory settings (Dhawan et al., 2009; Ganjisaffar et al., 2019; Sequeira et al., 2020).

Against subterranean termites (O. obesus), chlorantraniliprole, pyriproxyfen and chlorfenapyr were the most effective insecticides causing $80-85 \%$ mortality of termite workers in $72 \mathrm{~h}$ of exposure. These results are consistent with some previous studies showing effectiveness of chlorantraniliprole, chlorfenapyr and pyriproxyfen against different species of subterranean termites (Spomer et al., 2009; Mao et al., 2011; Manzoor et al., 2012; Neoh et al., 2012; Ma and Sui, 2013; Du et al., 2020). Moreover, our study findings substantiate the outcomes of a research work done by Akbar et al. (2019) which demonstrated 100\% mortality of O. obesus termite workers by chlorantraniliprole, chlorfenapyr and pyriproxyfen within $48 \mathrm{~h}$ of exposure. Moreover, these three differential chemistry insecticides were also found comparatively effective against subterranean termite infestations under field conditions (Jones et al., 2017; Du et al., 2020; Akbar et al., 2021).

\section{Conclusions and Recommendations}

It is concluded from the overall study results that neonicotinoid insecticides thiamethoxam, imidacloprid, clothianidin, nitenpyram, and tetramic acid-based insecticide spirotetramat were the most effective systemic insecticides against mango leafhoppers (I. clypealis), mealybugs (D. mangiferae) and citrus psyllids (D. citri), while the insecticides chlorantraniliprole, pyriproxyfen and chlorfenapyr were most effective against subterranean termites (O. obesus). Hence, these above mentioned biorational non-conventional and differential chemistry insecticides are recommended to the local farmers combating infestations of these insect pests.

\section{Acknowledgment}

Authors are grateful to Dr. Abu Bakar Muhammad Raza and Dr. Muhammad Asam Riaz for technically reviewing the manuscript. Authors declare no competing interest regarding the publication of this research work.

\section{Novelty Statement}

Among prevailing non-conventional differential chemistry synthetic insecticides, neonicotinoids (thiamethoxam, imidacloprid, clothianidin, nitenpyram) and spirotetramat were effective against mango leafhoppers, mealybugs and citrus psyllids, while the insecticides chlorantraniliprole, pyriproxyfen and chlorfenapyr were most effective against subterranean termites, and hence are recommended to the local farmers combating infestations of these insect pests in their crops.

\section{Author's Contributions}

Muhammad Zeeshan Majeed: Conceived the reseach idea, designed the experiments, prepared results 
and wrote the initial manuscript draft.

Muhammad Qasim, Gulfam Yousaf, Hamza Latif and Muhammad Zeeshan: Conducted the bioassays and recorded data.

Muhammad Luqman and Muhammad Irfan U1lah: Did the statistical analyses of data.

Dilbar Hussain: Revised and proofread the final draft.

Muhammad Zeeshan Majeed and Muhammad

Irfan Ullah: Gave the technical support for experiments.

\section{Conflict of interest}

The authors have declared no conflict of interest.

\section{References}

Afzal, M.B.S., S.A. Shad, N. Abbas, M. Ayyaz and W.B. Walker. 2015. Cross resistance, the stability of acetamiprid resistance and its effect on the biological parameters of cotton mealybug, Phenacoccus solenopsis (Homoptera: Pseudococcidae), in Pakistan. Pest Manage. Sci., 71(1): 151-158. https://doi.org/10.1002/ ps.3783

Ahmed, S., M.S. Nisar, B. Naseer, B. Hassan and M.M. Shakir. 2013. Determination of wood protection by seasoning and clove oil application against Odontotermes obesus Ramb (Termitidae: Isoptera). Pak. Entomol., 35(2): 83-87.

Ahmed, S., T. Mustafa, M.A. Riaz and A. Hussain. 2006. Efficacy of insecticides against subterranean termites in sugarcane. Int.J. Agric. Biol., 8: 508-510.

Akbar, M.F., M.A. Haq, F. Parveen, N. Yasmin and Khan, M.F.U. 2010. Comparative management of cabbage aphid (Myzus persicae (Sulzer) (Aphididae: Hemiptera) through bio and synthetic insecticides. Pak. Entomol., 32(1): 12-17.

Akbar, M.S., F. Sajjad, M. Afzal, M. Luqman, M.A. Riaz and M.Z. Majeed. 2021. Field evaluation of promising botanical extracts, plant essential oils and differential chemistry insecticides against subterranean termites Odontotermes obesus (Isoptera: Termitidae). Sarhad J. Agric., 37(1): 120-127. https://doi.org/10.17582/ journal.sja/2021/37.1.120.127

Akbar, M.S., M.Z. Majeed and M. Afzal. 2019. Comparative toxicity of selected newchemistry insecticides against subterranean termites Odontotermes obesus Ramb. (Isoptera: Termitidae). Sarhad J. Agric., 35: 20-26. https:// doi.org/10.17582/journal.sja/2019/35.1.20.26

Arif, M.J., W. Wakil, M.D. Gogi, R.R. Khan, M. Arshad, M. Sufyan and S. Majeed. 2018. Trends in sustainable management of emerging insect pests. In: Khan, I.A., Khan, M.S., editors. Developing Sustainable Agriculture in Pakistan. $1^{\text {st }}$ ed. CRC Press. Boca Raton. pp. 417-484. https://doi.org/10.1201/9781351208239-21

Byrne, F.J., M.P. Daugherty, E.E. GraftonCardwell, J.A. Bethke and Morse, J.G. 2017. Evaluation of systemic neonicotinoid insecticides for the management of the Asian citrus psyllid Diaphorina citri on containerized citrus. Pest Manage. Sci., 73(3): 506-514. https://doi.org/10.1002/ps.4451

Canale, M.C., A.F. Tomaseto, M.L. Haddad, H.D. Coletta-Filho and J.R.S. Lopes. 2017. Latency and persistence of 'Candidatus Liberibacter asiaticus' in its psyllid vector, Diaphorina citri (Hemiptera: Liviidae). Phytopathol., 107: 264272. https://doi.org/10.1094/PHYTO-02-160088-R

Chowański, S., M. Kudlewska, P. Marciniak and G. Rosiński. 2014. Synthetic Insecticides--is There an Alternative?. Polish J. Environ. Stud., 23(2): 291-302.

Dhawan, A.K., S. Kamaldeep and S. Ravinder. 2009. Evaluation of different chemicals for the management of mealy bug Phenacoccus solenopsis Tinsley on Bt cotton. J. Cot. Res. Dev., 23(2): 289-294.

Du, H., S. Zhang, Y. Chen, Y. Ke, S. Chen, X. Huang and Z. Li. 2020. Response variability of juvenile hormone and juvenile hormone analogs in workers of the Formosan subterranean termite (Coptotermes formosanus Shiraki). J. Asia-Pac. Entomol., 23(4): 1010-1013. https:// doi.org/10.1016/j.aspen.2020.08.010

Edwards, C.A. 2013. Environmental pollution by pesticides (vol.3). Springer Science and Business Media, New York. p. 542.

Elbert, A., M. Haas, B. Springer, W. Thielert and R. Nauen. 2008. Applied aspects of neonicotinoid uses in crop protection. Pest Manage. Sci., 64(11): 1099-1105. https://doi.org/10.1002/ ps.1616

Fiaz, M., M. Afzal and M.Z. Majeed. 2018a. Laboratory evaluation of three novel insecticides against Asian citrus psyllid, Diaphorina citri 
Kuwayama 1907 (Hemiptera: Psyllidae). J. Environ. Agric., 3(1): 282-288.

Fiaz, M., M. Afzal and M.Z. Majeed. 2018b. Synergistic action of Isaria fumosorosea Wize (Hypocreales: Cordycipitaceae) and spirotetramat against Asian citrus psyllid, Diaphorina citri Kuwayama (Hemiptera: Psyllidae) under field conditions. Pak. J. Agric. Res., 31(2): 194-201. https://doi.org/10.17582/ journal.pjar/2018/31.2.194.201

Ganjisaffar, F., S.A. Andreason and T.M. Perring. 2019. Lethal and sub-lethal effects of insecticides on the pink hibiscus mealy bug, Maconellicoccus birsutus (Hemiptera: Pseudococcidae). Insects, 10(1): 31. https://doi. org/10.3390/insects10010031

Ghafoor, H.A., M. Afzal, M. Luqman and M.Z. Majeed. 2019. Comparative toxicity of some selected novel chemistry insecticides against mealybug Drosicha Mangiferae (Hemiptera: Pseudococcidae) infesting citrus orchards in Pakistan. Pak. J. Agric. Res., 32(3): 428$434 . \quad$ https://doi.org/10.17582/journal. pjar/2019/32.3.428.434

Ghafoor, H.A., M. Afzal, M. Luqman, M.A. Javed, S.W. Hasan and M.Z. Majeed. 2020. Field evaluation of selected botanical and synthetic insecticides against mealybug Drosicha mangiferae Green (Hemiptera: Pseudococcidae) infesting citrus orchards in Pakistan. Pak. J. Agric. Res., 33(3): 454-460. https://doi. org/10.17582/journal.pjar/2020/33.3.454.460

Gulzar, A., M. Hafeez, K. Yousaf, M. Ali, M. Tariq and M.N. Tahir. 2015.Toxicity of some conventional insecticides against mango mealy bugs, Drosicha mangiferae. J. Sci. Int., 27(2): 1693-1695.

Gundappa, T.A. and P.K. Shukla. 2016. Seasonal dynamics of mango hoppers and their management under subtropics. GERF Bull. Biosci., 7(1): 6-9.

Gundappa, T.A. and P.K. Shukla. 2018. Population dynamics of mango mealybug, Drosicha mangiferae (Margorididae: Hemiptera) and its relation with weather parameters in subtropical climatic conditions. Ind. J. Agric. Sci., 88(6): 865-70.

Iqbal, J., H.N. Hussain, M. Latif, M.B. Baig, A.A. Owayss, H.S. Raweh and A.S. Alqarni. 2020. A field study investigating the insecticidal efficacy against Diaphorina citri Kuwayama on Kinnow mandarin, Citrus reticulata Blanco trees. Saudi J. Biol. Sci., 27(5): 1237-1241. https://doi. org/10.1016/j.sjbs.2020.02.006

Iqbal, N. and S. Saeed. 2013. Toxicity of six new chemical insecticides against the termite, Microtermes mycophagus D.(Isoptera:Termitidae: Macrotermitinae). Pak. J. Zool., 45: 709-713.

Ishaaya, I. and D. Degheele. 2013. Insecticides with novel modes of action: mechanisms and application (ed.). Springer Science and Business Media. ISBN: 978-3-662-03565-8.

Jha, S., J.C. Marak, N. Kasar, P. Barma and S. Chakrabarti. 2017. Population dynamics of mango hopper on 'amrapali' mango (Mangifera indica L.) and their species composition. Trend. Biosci., 10(15): 2752-2757.

Jones, S.C., E.L. Vargo, T.C. Keefer, P. Labadie, C.W. Scherer, N.T. Gallagher and R.E. Gold. 2017. Efficacy of chlorantraniliprole in controlling structural infestations of the eastern subterranean termite in the USA. Insects, 8(3): 92. https://doi.org/10.3390/insects8030092

Karar, H. and M.A. Bakhsh. 2018. Effect of host plant on abundance of mango hoppers, Idioscopus clypealis (Lethierry) (Hemiptera: Cicadellidae). Pak. Entomol., 40(1): 57-61.

Kaushik, D.K., S. Sharma, D. Sharma and U. Baraiha. 2014. Efficacy of insecticides against hopper complex on langra mango in Chhattisgarh. Pest. Res. J., 26(1): 6-11.

Khan, A.A., M. Afzal, A.M. Raza, A.M. Khan, J. Iqbal, H.M. Tahir, M.A. Aqeel. 2013 Toxicity of botanicals and selective insecticides to Asian citrus psylla, Diaphorina citri K. (Homoptera: Psyllidae) in laboratory conditions. Jokull J., 63: 52-72.

Kumar, A.A., A. Awasthi and G. Pandi. 2019. Evaluation ofinsecticides againstmango hoppers Amritodus atkinsoni and Idioscopus clypealis. Indian J. Entomol., 81(2): 340-342. https://doi. org/10.5958/0974-8172.2019.00052.X

Ma, Y. and X. Sui. 2013. Comparison on efficacy of chlorantraniliprole and bifenthrin against Coptotermes formosanus. Chin. J. Hyg. Insect. Equip., 19(4): 320-322.

Mahapatro, G.K. 2017. Can insecticide resistance be developed in termites?. Curr. Sci., 112(6): 1097-1098.

Mahmood, R., A. Rehman and M. Ahmad. 2014. Prospects of biological control of citrus insect pests in Pakistan. J. Agric. Res., 52: 229-244. 
Majeed, M.Z. 2012. Emissions of nitrous oxide by tropical soil macrofauna: impact of feeding guilds and microbial communities involved. Doctoral dissertation, University of Montpellier II, Montpellier, France.

Majeed, M.Z., M. Afzal, M.A. Riaz, K.S. Ahmed, M. Luqman, M.Z., Shehzad, M.B. Tayyab, M. Tanvir, S. Wahid. 2020. Comparative toxicity of phyto-extracts of indigenous flora of Soone valley against some insect pests of agricultural and urban importance. Punj. Univ. J. Zool. 35(2): 239-253. https://doi.org/10.17582/ journal.pujz/2020.35.2.239.253

Manzoor, F., A.H. Sayyed, T. Rafique and S.A. Malik. 2012.Toxicity and repellency of different insecticides against Heterotermes indicola (Isoptera: Rhinotermitidae). J. Anim. Plant Sci. 22(1): 65-71.

Mao, L., G.G. Henderson and C.W. Scherer. 2011. Toxicity of seven termiticides on the Formosan and eastern subterranean termites. J. Econ. Entomol. 104(3): 1002-1008. https://doi. org/10.1603/EC11005

Mirbahar, T.J., A.G. Lanjar, K.L. Khatri, B. Aslam, A.W. Solangi, R. Mehar-ul-Nissa, A.A. Kaleri and R.R. Kaleri. 2017. Impact of male trapping techniques through sticky color traps on the development of population of mango mealybug, Drosicha mangiferae (Green) (Hemiptera: Margarodidae). Pak. Entomol., 39(2): 5-8.

Naeem, A., S. Freed, F.L. Jin, M. Akmal and M. Mehmood. 2016. Monitoring of insecticide resistance in Diaphorina citri Kuwayama (Hemiptera: Psyllidae) from citrus groves of Punjab, Pakistan. Crop Prot., 86: 62-68. https:// doi.org/10.1016/j.cropro.2016.04.010

Nazir, T., M.D. Gogi, M.Z. Majeed, W. ul Hassan, A. Hanan and M.J. Arif. 2017. Field evaluation of selective systemic formulations against sucking insect pest complex and their natural enemies on a transgenic Bt cotton. Pak. J. Zool., 49(5): 789-1796. https://doi.org/10.17582/ journal.pjz/2017.49.5.1789.1796

Neoh, K.B., J. Hu, B.H. Yeoh and C.Y. Lee. 2012. Toxicity and horizontal transfer of chlorantraniliprole against the Asian subterranean termite Coptotermes gestroi (Wasmann): effects of donor: recipient ratio, exposure duration and soil type. Pest Manage. Sci., 68(5): 749-756. https://doi.org/10.1002/ ps. 2322
Nicolopoulou-Stamati, P., S.Maipas, C. Kotampasi, P. Stamatis and L. Hens 2016. Chemical pesticides and human health: the urgent need for a new concept in agriculture. Front. Public Heal., 4: 148. https://doi.org/10.3389/ fpubh.2016.00148

Oberemok, V.V., K.V. Laikova, Y.I. Gninenko, A.S. Zaitsev, P.M. Nyadar and T.A. Adeyemi. 2015. A short history of insecticides. J. Plant Prot. Res., 55(3): 221-226. https://doi.org/10.1515/ jppr-2015-0033

Qureshi, M.S., B. Thistleton, S.S. Syeda, M. Hearnden and M.H. Qureshi. 2011. Managing mango leafhoppers and other associated species affected through systemic insecticides in mango orchards at Darwin, Australia. Pak. J. Entomol., 26(2): 81-87.

Rasib, K.Z., W. Hidayat and A. Aihetasham. 2017. Feeding preferences and control of a Pakistani termite Odontotermes obesus (Rambur) (Isoptera, Rhinotermitidae). Annu. Res. Rev. Biol., 18: 1-13. https://doi.org/10.9734/ ARRB/2017/36225

Razi, M.F., M.L. Keremane, C. Ramadugu, M. Roose, I.A. Khan and R.F. Lee. 2014. Detection of citrus huanglongbing-associated 'Candidatus Liberibacter asiaticus' in citrus and Diaphorinacitri in Pakistan, seasonal variability, and implications for disease management. Phytopathol., 104: 257-268. https://doi.org/10.1094/PHYTO08-13-0224-R

Sequeira, R.V., M. Khan and D.J. Reid. 2020. Chemical control of the mealybug Phenacoccus solenopsis (Hemiptera: Pseudococcidae) in Australian cotton: glasshouse assessments of insecticide efficacy. Aust. Entomol., 59(2): 375385. https://doi.org/10.1111/aen.12446

Singh, V., N. Sharma and S.K. Sharma. 2016. A review on effects of new chemistry insecticides on natural enemies of crop pests. Int. J. Sci. Environ. Technol., 5(6): 4339-4361.

Spomer, N.A., S.T. Kamble and B.D. Siegfried. 2009. Bioavailability of chlorantraniliprole and indoxacarb to eastern subterranean termites (Isoptera: Rhinotermitidae) in various soils. J. Econ. Ent., 102(5): 1922-1927. https://doi. org/10.1603/029.102.0524

Stansly, P.A. and J.A. Qureshi. 2007. Insecticidal control of Asian citrus psyllid through foliar applications on orange, 2006. Arthrop. Manage. Test., 32(1): D10. https://doi.org/10.1093/ 
amt/32.1.D10

Tahir, H.M., I. Nazarat, S. Naseem, A. Butt, R. Yaqoob, M.K. Mukhtar and K. Samiullah.2015. Seasonal dynamics of spiders and insect pests in citrus orchards of district Sargodha, Pakistan. Pak. J. Zool., 47: 1673-1681.

Teixeira, C.D., C. Saillard, S. Eveillard, J.L. Danet, A.J. Ayres and J. Bové. 2005. 'Candidatus Liberibacter americanus', associated with citrus huanglongbing (greening disease) in São Paulo State, Brazil. Int. J. Syst. Evol. Microbiol., 55: 1857-1862.

https://doi.org/10.1099/ ijs.0.63677-0

Tiwari, S., R.S. Mann, M.E. Rogers and L.L. Stelinski. 2011. Insecticide resistance in field populations of Asian citrus psyllid in Florida. Pest Manage. Sci., 67(10): 1258-1268. https:// doi.org/10.1002/ps.2181

Tong, H., Q. Su, X. Zhou and L. Bai. 2013. Field resistance of Spodoptera litura (Lepidoptera: Noctuidae) to organophosphates, pyrethroids, carbamates and four newer chemistry insecticides in Hunan, China. J. Pestic. Sci., 86: 599-609. https://doi.org/10.1007/s10340-0130505-y

Venkatesan, T., S.K. Jalali, S.L. Ramya and M. Prathibha. 2016. Insecticide resistance and its management in mealybugs. In: Mani, M., Shivaraju, C., editors. Mealybugs and their management in agricultural and horticultural crops. Springer, New Delhi. pp. 223-229. https://doi.org/10.1007/978-81-322-26772_17 